\title{
Prognostic Impact of TEL-AML-1 Fusion Gene on Acute Lymphoblastic Leukemia
}

Wijdan N. Ibrahim ${ }^{1}$, Hassan J. Hasony ${ }^{1}$, Jinan Gh Hassan ${ }^{2}$

${ }^{1}$ Department of Microbiology, College of Medicine, Basrah, Iraq.

${ }^{2}$ Department of Pediatrics, College of Medicine, Basrah, Iraq.

\section{ABSTRACT}

The TEL-AML-1 fusion gene resulting from 12:21 chromosomal translocation is believed to be the most common molecular genetic abnormality in childhood acute lymphoblastic leukemia (ALL). This study was conducted to investigate the frequency of this fusion gene in children suffering from ALL attending the oncology unit in the Basrah Hospital for Pediatric and Gynecology during the period May 2009 to April 2010, and point out the different laboratory features associated with this anomaly.

A total of 120 blood samples were collected (60 early-diagnosed ALL children and 60 healthy children as control group). The controls were matched with cases by age and sex. Ribonucleic acid (RNA) was successfully extracted from the fresh blood of 40 ALL cases used for the detection of TEL-AML-1 fusion gene by reverse transcriptase-polymerase chain reaction $(R T-P C R)$.

Of the newly diagnosed ALL cases, $27.5 \%$ were positive for TEL-AML-1 fusion gene as well as $5 \%$ among the control group. All TEL-AML-1 positive cases showed an age peak between 3 and 6 years and tend to occur more frequently among females than males. The TEL-AML-1 positive cases were classified as the standard-risk group and accounted for $72.3 \%$, while $27.3 \%$ were the high-risk group $(P<0.05)$. According to the French-American-British classification criteria, $72.3 \%$ of the high-risk and $68 \%$ of the standard-risk groups belong to the L2 stage.

The TEL-AML-1 fusion gene identifies a subset of pediatric ALL associated with a number of laboratory markers of good prognosis and should thus be considered in routine molecular work of ALL to confirm its impact on clinical outcome and to design a suitable therapy.

Key words: Acute lymphoblastic leukemia, TEL-AML-1, fusion gene

\section{INTRODUCTION}

AML-1 is normally expressed in all hematopoietic lineage and acts to regulate the expression of various genes such as granulocyte-colony stimulating factor, interleukin-3, T-cell receptors, and myeloperoxidase genes (1). Frequent translocation variants result in fusion between intron-5 of TEL and intron-2 of AML-1 (2). The t(12:21) results in the chimeric fusion gene TEL-AML-1. The basis of this selectivity is an important unresolved issue (3), but most likely reflects a selective impact of the chimeric protein on the proliferation and/or survival of B-cell precursor (4). Although the mechanism of leukemogenesis induced by TEL-AML-1 remains obscure, recent data have demonstrated the importance of both TEL and AML-1 for normal hematopoiesis, thus suggesting that the presence of TEL-AML-1 fusion protein leads to disordered hematopoietic development as a critical component (5). 
There is a persuasive evidence that TEL-AML-1 usually arises prenatally as an early or initiating mutation. The data provide convincing evidence that TEL-AML-1 translocation is the initiating event in leukemia $(6,7)$. The latency between birth and onset of leukemia clearly demonstrates the need for important secondary and postnatal events in the promotion of ALL with TEL-AML-1 fusion $(8,9)$ since the second nontranslocated TEL allele is often deleted in t(12:21)-positive ALL patients (up to $70 \%$ ). This deletion is generally considered as the second hit in the leukemogenesis (7).

The favorable prognostic impact of TEL-AML-1 is independent of age and leukocyte count and was consistently favorable among patients treated on several different protocols. Thus, TEL-AML-1 expression identifies a large subset of B-precursors ALL patients who may be candidate for less intensive therapy (10-13). The fusion genes generated by chromosome translocation (TELAML-1 in ALL) primarily blocks cell differentiation. The aberrant proteins produced by these genes inhibit gene activity and differentiation by recruiting repressor molecules. These repressors include histone deacetylase enzyme (14).

Investigators have reported that almost 10\%-28\% of relapsed pediatric ALL patients express the TEL-AML-1 fusion, but the relapse of patients with TEL-AML-1 fusion is not always associated with poor prognosis (15).

This study aimed at determining the frequency of TEL-AML-1 fusion gene status in children with newly diagnosed ALL and to predict its association with prognostic laboratory features.

\section{MATERIALS AND METHODS}

A case-control study was conducted during the period May 2009 to April 2010 on 60 consecutive children of below 15 years of age with newly diagnosed, untreated cases of acute lymphoblastic leukemia (ALL). mRNA was successfully extracted from 40 cases (20 females and 20 males). The primary diagnosis of ALL cases was based on the complete blood picture and bone marrow aspirates. An age of 1-9.99 years and white blood cell (WBC) count less than $50 \times 10^{\circ} / \mathrm{L}$ was considered as standardrisk criteria, with all other combinations of these features (central nervous system infiltration, hepatosplenomegaly) as high risk. The diagnosis and staging of ALL cases were based on the standard French-American-British (FAB) morphological and cytological criteria by specialist hematologist, and then referred to the leukemia treatment unit at the Basrah Hospital for Pediatric and Gynecology. Sixty healthy children matched by age and sex (31 male and 29 females) from the general population of Basrah (school children and day care centers at the city center, Abu-Alkhasib, Al-Hartha) with negative history of major illness and no history of cancers or any apparent congenital anomalies were recruited as the control group.

Blood was drawn from the veins of both patients and control; 3 $\mathrm{mL}$ of venous blood taken in EDTA tubes was used immediately for total RNA extraction using the QIAamp@RNA Blood Mini Kit (Qiagen GmH, Germany). All steps of the procedure were followed according to the manufacturer's instructions. Isolated total RNA was stored at $-20^{\circ} \mathrm{C}$ in RNase-free distilled water where no degradation of RNA was detected [Qiagen (16)]. The integrity of RNA was assessed by electrophoresis through 1\% agarose gel containing 1.3 iM ethidium bromide.

Polymerase chain reaction $(P C R)$ analysis of fusion genes was based on the design of oligonucleotide primers at opposite sides of breakpoint regions, so that the $P C$ R product contains the tumorspecific fusion sequences. However, many acute leukemia fusion genes are transcribed into fusion mRNA, which can serve as the $P C R$ target after reverse transcription (RT) in copy-DNA (CDNA). So in this study, TEL-AML-1 fusion transcript was detected by RT-PCR techniques, which was carried out on the extracted RNA using Qiagen one-step RT-PCR Kit following the manufacturer's instructions. The PCR product from the amplification of TELAML-1 fusion gene was detected by two sets of primers obtained from Alpha-DNA (Canada), which were as follows:

\section{TEL-A: (5'-TGCACCCTCTGATCCTGAAC-3') and AML-1B: (5'-AACGCCTCGCTCATCTTGC-3').}

These were then electrophoresed on ethidium bromide-stained $2 \%$ agarose gel. The entire gel was subjected to equal electric current together with the internal control and ladder markers. The presence of 298 bp bands indicates breakpoint in AML-1 intron-1 whereas their absence indicates the null fusion and considered as negative result (17). 


TABLE 1: Distribution of TEL-AML-1 fusion gene in the study
population
\begin{tabular}{llll}
\hline $\begin{array}{l}\text { TEL-AML-1 } \\
\text { Fusion gene }\end{array}$ & $\begin{array}{l}\text { Study } \\
\text { group } \\
N(\%)\end{array}$ & $\begin{array}{l}\text { Control } \\
\text { group } \\
N(\%)\end{array}$ & $\begin{array}{l}\text { Total } \\
N(\%)\end{array}$ \\
\hline Positive & $11 / 40(27.5)$ & $3 / 60(5)$ & $14 / 100(14)$ \\
Negative & $29 / 40(72.5)$ & $57(95)$ & $86 / 100(86)$ \\
TOTAL & $40(100)$ & $60(100)$ & $100(100)$ \\
\hline & & & \\
$\chi^{2}$ (Chi-Square) $=10.09 ;$ df (degree of freedom) $=1 ; P=0.002$
\end{tabular}

\section{RESULTS}

The distribution of TEL-AML-1 transcript in the study population is summarized in Table 1, which shows that a total of 100 children, 40 of them suffering from ALL, were successfully investigated for the presence of TEL-AML-1 fusion gene. The TEL-AML-1 fusion gene was expressed in $27.5 \%$ of ALL cases and in 5\% of healthy control group. The difference was statistically significant $(P<0.05)$.

The distribution of ALL patients according to the FAB classification in relation to risk grouping is presented in Table 2. Out of the total ALL cases, $62.5 \%$ were classified as the standard-risk group and $37.5 \%$ as the high-risk group. However, according to the $F A B$ classification, 68\% of the standard-risk group belong to the $L 2$ stage, while $73.3 \%$ of ALL cases in the high-risk group were in the L2 stage. This difference was statistically not significant $(P>0.05)$.

The distribution of TEL-AML-1 fusion gene according to sex among the study population is summarized in Table 3. No significant effect was noted with regard to sex on the distribution of TEL-AML-1 fusion genes $(P>0.05)$.

The distribution of TEL-AML-1 fusion genes according to different age groups is described in Table 4, which shows no significant effect with regard to age on the presence of fusion genes $(P>0.05)$.

\section{DISCUSSION}

ALL is the most common malignancy of childhood. Cure of many of ALL children is difficult to predict and is considered an individual response of a patient to chemotherapy (18). It is likely that this clinical heterogeneity reflects a diverse pathogenesis of leukemia. The molecular basis of childhood ALL is largely
TABLE 2: Distribution of ALL patients according to the FAB classification and risk group ${ }^{2}$

$\begin{array}{rlll}\text { FAB } & \text { Standard risk } N(\%) & \text { High risk } N(\%) & \text { Total } N(\%) \\ \text { L1 } & 7(28) & 1(6.7) & 8(20) \\ \text { L2 } & 17(68) & 11(73.3) & 28(70) \\ \text { L3 } & 1(4) & 3(20) & 4(10) \\ \text { Total } & 25(62.5) & 15(37.5) & 40(100)\end{array}$

an age of 1-9.99 years and a leukocyte count less than $50 \times 10 / L$ were considered as standard-risk criteria with all other combinations of these features considered high risk.

$\chi^{2}=4.571 ; \mathrm{df}=2 ; \mathrm{P}>0.05$

unknown. Furthermore, it is likely that significant advance in the treatment of childhood ALL will depend on a better understanding of the molecular events that causes the disease (18-20). Chromosomal abnormalities in childhood ALL had important significance related to diagnosis, management, and prognosis. Understanding of leukemogenesis is enhanced by the identification of specific chromosomal alterations that pinpoint sites for molecular studies to identify genes involved in the transformation and proliferation of leukemic cells $(20,21)$.

TABLE 3: Distribution of TEL-AML-1 fusion gene in relation to sex

\begin{tabular}{lcccc}
\hline TEL-AML-1 & \multicolumn{2}{c}{ Study (ALL) group } & \multicolumn{2}{c}{ Control group } \\
\cline { 2 - 5 } fusion gene & Male & Female & Male & Female \\
& $N(\%)$ & $N(\%)$ & $N(\%)$ & $N(\%)$ \\
\hline Positive & $5(25)$ & $6(30)$ & $1(3.2)$ & $2(6.9)$ \\
Negative & $15(75)$ & $14(70)$ & $30(96.8)$ & $27(93.1)$ \\
Total & $20(100)$ & $20(100)$ & $31(100)$ & $29(100)$ \\
\hline
\end{tabular}

$\chi^{2}=0.125, \mathrm{df}=1, \mathrm{NS} ; \mathrm{EFT}=0.425, \mathrm{df}=1, \mathrm{NS}$

TABLE 4: Distribution of TEL-AML-1 fusion genes according to age of ALL patients

\begin{tabular}{lcccc}
\hline \multirow{2}{*}{$\begin{array}{c}\text { Age groups } \\
\text { (years) }\end{array}$} & \multicolumn{4}{c}{ TEL-AML-1 fusion genes } \\
\cline { 2 - 5 } & \multicolumn{2}{c}{ Study group } & \multicolumn{2}{c}{ Control group } \\
\cline { 2 - 5 } & $\begin{array}{c}\text { Positive } \\
N(\%)\end{array}$ & Negative & Positive & Negative \\
\hline 5 & $6(54.5)$ & $18(62.1)$ & $1(33.3)$ & $36(63.2)$ \\
$5-10$ & $5(45.5)$ & $7(24.1)$ & $2(66.7)$ & $18(31.6)$ \\
$>10$ & $0(0)$ & $4(13.8)$ & $0(0)$ & $3(5.3)$ \\
Total & $11(27.5)$ & $29(72.5)$ & $3(5)$ & $57(95)$ \\
\hline
\end{tabular}

$\mathrm{EFT}=2.8, \mathrm{df}=2, \mathrm{P}>0.05$ 
In the present study, the frequency of TEL-AML-1 gene fusion was $27.5 \%$ in patients with ALL and $5 \%$ in the control group. Other studies on newly diagnosed ALL cases reported frequencies varying from $2 \%$ to $33 \%$ (23-30). The highest frequency (33\%) was reported by a French group (22) and the lowest came from a Spanish group by Garcia-Sanz et al (23). The present-study figure (27.5\%) in newly diagnosed ALL cases seems to lie on the higher side of the reported frequencies. Comparable to the presentstudy results were those reported from Brazil (18\%) (24), Italy and Germany (19\%),29 the Czech Republic (22\%) (27), and the United States (22\% and 27\%) $(25,26)$. Lower percentages were reported from India (9\%) (28) and the United Kingdom (11\%) (30). Most of the aforementioned researchers used the RT-PCR technique for the basic analysis of TEL-AML-1 fusion gene, while some complemented their analysis by southern blotting or fluorescent in situ hybridization. However, the varying frequencies in any method used indicates that the different methodologies employed have more or less close sensitivity and specificity levels in detecting the fusion gene in question, so they cannot be held responsible for such variations, but can be attributed to the usage of different sets of primers. Furthermore, by using RT-PCR strategies, it was found that a significant proportion of healthy individuals (5\%) harbor the TEL-AML-1 gene rearrangement. These cases have same residency that may give an idea that the area was exposed to same environmental factors such as radiation or due to exposure to an outbreak of viral infection. However, another study reported a frequency of $8.8 \%$ (31). It seems that the underlying molecular mechanisms may play an additional role in the pathogenesis and in determining the clinical outcome of this subset (32).

This report and others like it raise a number of interesting questions. Does the presence of an oncogenic fusion gene detected by RT-PCR confer an increased risk to develop leukemia? Or, what obligation does one have to report or follow-up on RT$P C R$ positivity for a known oncogene in a healthy individual? At a minimum, investigators engaged in such analyses should consider the design and implementation of studies that would allow for assessment of relative risk of leukemia based on the presence of RT-PCR detectable fusion genes (31).
Clinical and laboratory features with recognized prognostic values in the childhood ALL include age, sex, initial total WBC count, degree of organomegaly, and early response to therapy $(32,33)$. These variables have consistently emerged as independent predictors of outcome in almost all therapeutic studies. Age and WBC count are continuous variables, and discrete thresholds used for risk stratification are somewhat arbitrary (34). It was found that $62.5 \%$ of TEL-AML-1 positive cases were classified as the standard-risk group, while $37.5 \%$ of them had been classified as high-risk patients in spite of harboring TEL-AML1 rearrangement. These high-risk patients will be subjected to unnecessary combination of drugs with their side effects and acute toxicity and late-occurring adverse events in addition to the cost of these drugs on the patient (35). The present-study results are consistent with other reports on clinical features and significance of TEL-AML-1 positive cases $(27,36)$. In addition, the favorable impact of TEL-AML-1 is independent of age and leukocyte count.11 However, all the TEL-AML-1 positive cases in the study and control groups were below 6 years old, thus assigning the TEL-AML-1 positive patients to the standard-risk group. These can be considered as factors in favor of TEL-AML-1 fusion gene as a marker for good prognosis.

\section{REFERENCES}

1. Roumier $C$, Fenaux $P$, Lafage $M$, et al. New mechanisms of AML1 gene alteration in hematological malignancies. Leukemia 2003, 17: 9-16.

2. Jim VD, Macintyre EA,Gabert A, et al. Standardized RTPCR analysis of fusion gene transcript from chromosome aberrations in acute leukemia for detection of minimal residual disease. Leukemia 1999, 13:1901-1928.

3. Kazunori N, Mary S, Kenneth B. Age difference in immunophenotype of acute leukemia. Am J Immunol 2006, 2(3): 64-70

4. Arthur Z, Mel G, Tariq E. Role of TEL-AML-1 fusion gene in the molecular pathogenesis of childhood acute lymphoblastic leukemia. Oncogene 2004, 23: 4275-4283.

5. Rubnitz JE, Pui CH, Downing JR. The role of TEL fusion gene in pediatric leukemia. Leukemia 1999, 13(1): 6-13 (ISSN: 08876924)

6. Armstrong SA and Look TA. Molecular genetics of acute lymphoblastic leukemia. J Clin Oncology (Rev Article) 2005, 23(26): 6306-6315.

7. Anthony MF, Chiara P, Clara B, et al. The TEL-AML-1 leukemia fusion gene dysregulates the TGE-B pathway in early $B$ lineage progenitor cells. J Clin Invest 2009, 119(4):826-836. 
8. Charles GM, Salil G, Ina $R$, et al. Genome-wide analysis of genetic alteration in acute lymphoblastic leukemia. Nature 2007, 446:758-764.

9. Jaro-ova $M$, Holzerova M, Mihal V, et al. Additional evidence of genetic changes in children with ALL and TEL-AML-1 fusion gene. Leukemia 2002, 16: 1873-1875.

10. Andersen MT, Nordentoft I, Hjalgrim LL, et al. Characterization of $t(12: 21)$ breakpoint junctions in acute lymphoblastic leukemia. Nature 2001, 15 (5): 858-859.

11. Scott AA and LookAT. Molecular genetics of acute lymphoblastic leukemia. J Clin Oncology 2005, 23: 26

12. Fabio $T$ and Maurizio $A$. Treatment of pediatric acute lymphoblastic leukemia, haematologica 2008, 93(8): 11241128.

13. Artigas A, Carmen G. Frequency of TEL-AML-1 and BCR-ABL fusion genes in children with acute lymphoblastic leukemia. Rev Ned Chile (online) 2006, 134(11): 1367-1376.

14. Jukka K. Prognostic factors in childhood acute lymphoblastic leukemia (ALL), PhD thesis submitted to Haartman Institute University of Helsinki, Finland 2001.

15. Anthony MF, Karin F, Renate $\mathrm{PE}$, et al. Origine of "late" relapse in childhood lymphoblastic leukemia with TEL-AML-1 fusion genes. Blood 2001, 98(3): 558-564.

16. Marks D, Kurz BW, Link MP, et al. High incidence of potential P53 inactivation in poor outcome childhood acute lymphoblastic leukemia at diagnosis. Blood 1996 87(3): 1155-1161.

17. Shaker HM, Sidhom IA, El-Attar IA. Frequency and clinical relevance of TEL-AML-1 fusion gene in childhood acute lymphoblastic leukemia in Egypt. J Egypt Natl Cancer Instit 2001, 13(1): 9-18.

18. Fatih $\mathrm{MU}$, Niels $\mathrm{Pb}$, Peter $\mathrm{H}$,Christopher $\mathrm{N}$, et al. Expression of TEL-AML-1 fusion transcript and response to induction therapy in standard risk acute lymphoblastic leukemia. Leukemia and Lymphoma 2001, 42(1\&2): 41-56.

19. Mosad E, Hamed BH, Bakry MR, et al. persistence of TELAML-1 fusion gene as minimal residual disease has no additive prognostic value in CD10 positive B-acute lymphoblastic leukemia: a FISH study. J Hematol Oncology 2008, 1: 17 (available at http://www.jhoonline.org/content/1/ 1/17

20. Einav U. Class discovery in acute lymphoblastic leukemia using gene expression analysis. MSc thesis, Scientific council of the Weizmann, 2003.

21. Nina A. P53 protein biosignitures in acute myeloid leukemia. MSc thesis, University of Bergen 2006.
22. Cave H, Cacheux V, Raynaud S, et al. ETV6 is the target of chromosome $12 p$ deletion in $t(12: 21)$ childhood acute lymphoblastic leukemia. Leukemia 1997, 11: 1459-1464.

23. Garcia-Sanz R, Alaejos I, Orfao A, et al. Low frequency bof the TEL-AML-1 fusion gene in acute lymphoblastic leukemia in Spain. Br J Hematol 1999, 107: 667-669.

24. Magalhaes IG, Pombo-de-Oliveira MS, Bennett CA, et al. TELAML-1 fusion gene frequency in pediatric acute lymphoblastic leukemia in Brail. Br J Hematol 2000, 11(1): 204-207.

25. McLean TW, Ringold S, Neuberg D, et al. TEL-AML-1 dimerizes and is associated with a favourable outcome in childhood acute lymphoblastic leukemia. Blood, 1996, 88: 4252-4258.

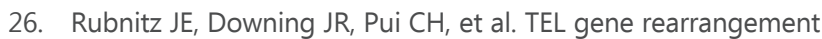
in acute lymphoblastic leukemia: a new genetic marker with prognostic significance. J Clin Oncol 1997, 15:1150-1157.

27. Zuna J, Hrusak $O$, Kalinova $M$, et al. TEL-AML-1 positivity in childhood ALL: average or better prognosis? Czech Pediat Hematol Working Group. Leukemia 1999, 13: 22-24.

28. Inamdar $\mathrm{N}$, Kumar SA, Banavali SD, et al. Comparative incidence of the rearrangement of TEL-AML-1 and ALL1 gene in pediatric precursor B acute lymphoblastic leukemia in India , Int J Oncol 1998, 13 : 1319-1322.

29. Eguchi-Ishimae M, Eguchi M, Tanaka K, et al. Fluorescence insitu hybridization analysis of 12; 21 translocation in Japanese childhood acute lymphoblastic leukemia. Japn J Cancer Res 1998, 89: 783-788.

30. Spathas DH, Stewart J, Singer IO, et al. Detection of t(12:21) in childhood lymphoblastic leukemia by fluorescence instu hybridization. Cancer Genel Cytogenet 1999, 110: 7-13.

31. Gary GD. Origin and clinical significance of the TEL-AML-1 fusion. Blood 2001, 97 (3): 73

32. Greaves M. Aetiology of acute lymphoblastic leukemia. Lancet 1997, 349:344-349

33. Pui CH. Childhood leukemia. N Engl J Med 1995, 332:16181630.

34. William LC, Deepa B, Dong-Joon $M$, et al. Pediatric acute lymphoblastic leukemia. Am Soc Hematol 2003, 29(2): 49-50

35. Petridou E, Dalamaga $M$, Mentis $A$, et al. Evidence on the infectious aetiology of childhood leukemia: the role of low herd immunity (Greece). Cancer Causes Control 2001, 12: 645-652.

36. Harbott J, Viehmann S, Borkhardt A, et al. Incidence of TELAML-1 fusion gene analysed consecutively in children with acute lymphoblastic leukemia in relapse. Blood 1997, 90: 49334937. 